\title{
A Survey Research of College Students' Learning Engagement
}

\author{
Yufeng Lu* \\ School of Mechanical and Automotive Engineering, \\ QILU University of Technology, \\ Jinan, China \\ luyf78@126.com
}

\begin{abstract}
According to the characteristics of the study, referring to the American NSSE questionnaire, the college students' learning engagement was transformed into the following five dimensions: learning harvest, active learning, attitude investment, time investment, learning methods. Taking a professional student as a case study, through the collation and analysis of the questionnaire, to find out what personal background factors lead to differences in learning investment, and what needs to be improved in this particular campus environment. There were two majors and two grades in the survey objects. A total of 186 questionnaires were sent out and 179 valid questionnaires were obtained with an effective rate of 96.2\%. According to the survey results, we found that college students lack of investment. We should strengthen the construction of the class atmosphere. And let students know that learning engagement has a lot to do with individuals.
\end{abstract}

Keywords-Students' learning engagement; Class atmosphere; Learning investment; Individuals

\section{INTRODUCTION}

According to the characteristics of the study, referring to the American NSSE questionnaire, the college students' learning engagement was transformed into the following five dimensions: academic atmosphere, cooperative learning, teacher-student interaction, campus environment support, and the richness of educational experience. Taking a professional student as a case study, through the collation and analysis of the questionnaire, to find out what personal background factors lead to differences in learning investment, and what needs to be improved in this particular campus environment. According to the survey results, we found that college students lack of investment. We should strengthen the construction of the class atmosphere. And let students know that learning engagement has a lot to do with individuals.

Since 1990s, China's higher education has rapidly entered the stage of popular development. At the same time, the quality of higher education has increasingly become the focus of attention from all walks of life [1]. Our school was approved as the first batch of key characteristic schools in Shandong in 2012, and our school will turn from college to university, which puts forward higher requirements for the quality of undergraduate education in our university. Drawing on the practice of improving the quality of education in universities such as the United States, Canada and other countries, we propose to investigate the learning engagement of college students in our university. The survey of college students learning situation commitment, factor analysis into the influence of College Students' learning, put forward the corresponding measures to promote the improvement of student engagement, provided to solve the problem of education quality has become the main task of this paper.

As early as 1930s, Taylor pointed out that the more time students spend on learning, the more knowledge they learn [2]. Since then, C.Pace's "quality " theory and Astin's "student input" theories all think that students' time and concentration of learning affect the learning effect together. Only when students actively put the activities into the school to learn better, students' learning is the whole process of students' learning engagement and participation [3]. Pascarella's "change assessment model" holds that students' cognitive development is directly affected by students' prior experience, the degree of communication with teachers and peers, and the degree of individual effort. The structure and organizational characteristics of the University indirectly affect the students' achievement through the campus environment, teacher-student relationship, the relationship between students and students, and the degree of individual efforts of students [4]. O.Eileen and Rernolds and many other researchers found through empirical research: There is a positive correlation between students' learning engagement, learning motivation, attendance, academic achievement, problem-solving ability, and other indicators of students' development quality. A. Chickering proposed 7 ideal behavior of undergraduate education: a good teacher-student relationship, a good partner relationship, students active learning attitude, a learning task devoted time, teacher feedback, teachers of students with high expectations and diverse campus environment based on the hypothesis of students' learning engagement reflecting the quality of undergraduate education indirectly. Astin and Kuhn also proposed to see whether it can promote students better into the activities of the school to measure the quality of a university education.

Learning engagement reflects the degree of students' involvement in learning, reading and writing in class, communicating with students and teachers, learning and research activities. Learning engagement reveals the students' 
learning state and the policy and environment of school support learning, and it can effectively predict the achievement of students' learning development, which is comparable in different institutions and departments. At the same time, the information collection of students' learning activities is easy to operate and low cost. More importantly, learning engagement evaluation pays more attention to the students' learning experience and the quality of development, paying attention to university support student learning into the teaching ability and the campus environment can help university teachers and students in the classroom to confirm input learning, to better understand the influence of development of university education for students, and continuously improve the education plan, really the core goal of education to students as the main body. It also provides a reference for the quality of higher education in addition to the social prestige and resources for government decision-making, public choice of schools, academic counseling and education research. Therefore, if learning engagement is regarded as an important monitoring basis of undergraduate education quality and integrated into undergraduate education evaluation activities, it will help guide university and teachers to create a humanistic learning environment for students. It can also help students combine the school environment with their personal experience, and make full use of the existing resources of the school, so that students can acquire the method and ability of learning and self learning, and promote the all-round development of students. At the same time, educators and evaluators recognize that the most important thing for undergraduate education quality evaluation is to evaluate the talent training task and target realization, and to transfer the evaluation of "things" and external conditions to the evaluation of human development [5].

\section{RESEARCH PROCESS}

\section{A. Research ideas}

Under the new situation, China's auto industry is facing a huge challenge of strengthening independent innovation, energy saving and environmental protection and cultivating independent brands, which puts forward higher and more urgent requirements for the training of senior talents of vehicle engineering. The demand for talents in the automotive industry has changed to diversified and applied innovative talents. The traditional training model is mostly one-way, there are many problems in the process of personnel training, personnel training mode, such as a single cooperative education is not closely enough, graduates of engineering consciousness and practice ability, practical ability and innovative ability is not competent for the job requirements, the theory and practice of a certain degree of touch and so on. This urgently needs a new type of talent training mode to meet the needs of the industry. In order to establish an appropriate training method, it is necessary to study the students' learning engagement.

Take the students in our university as the object of this study. Investigate their efforts to participate in curricular and extracurricular activities in the past 1 year, and evaluate their self harvest. Our college students learning engagement was analyses based on the result.

\section{B. Methods}

There two methods were used in this paper.

(1) Questionnaire survey is also called "written survey", or "fill in the law". In indirect means, collect research materials in written form. Take the way to obtain information and materials indirectly by filling out a brief consultation form (questionnaire) to the investigator and asking to fill in the opinions and suggestions about the problems concerned. According to the characteristics of this study, referring to the American NSSE questionnaire, the students' learning engagement was transformed into the following five dimensions: learning harvest, active learning, attitude investment, time investment, learning methods.

(2) A continuous investigation of an individual, a group, or an organization for a long period of time. Thus, the whole process of behavior development and change is studied. This research method is also called case study method. Taking the students majoring in automobile as a case study, through the collation and analysis of the questionnaire, to find out what personal background factors lead to differences in learning investment in this particular campus environment, and what aspects need to be improved.

\section{Research content}

Through the investigation of academic achievement and learning engagement of college students in our college, we get the cognition and satisfaction of college students on academic achievement and learning engagement. We will find an effective way to effectively improve the academic performance of College students. This paper puts forward corresponding strategies and measures to improve their learning situation and improve their learning enthusiasm, so as to enable college students to develop rapidly, comprehensively and healthy.

(1) The investment in learning majors in automobile in Qilu University of technology.

(2) Influencing factors of College Students' learning engagement.

(3) To explore the problems reflected in the related research of College Students' learning engagement, and put forward corresponding suggestions.

\section{RESEARCH RESULTS}

\section{A. Basic Situation}

A total of 186 questionnaires were sent out, 186 were recovered, and the recovery rate was $100 \%$. Part of the questionnaire with incomplete answers and all answers for the same value were considered invalid and 179 valid questionnaires were obtained, with an effective rate of $96.2 \%$.

Among the 186 respondents, 74 were in grade 2010, accounting for $39.8 \%$; the rest were grade 11 students. They are major in automotive service engineering, mechanical design and manufacturing and automation professional. 


\section{B. Quantitative Methods of Learning Engagement}

Through exploratory factor analysis, we can conclude that learning engagement is a multidimensional structure. We can quantify learning engagement through 5 dimensions: learning harvest (4 projects: I feel very substantial because of study, Learning makes me get more people's approval, Learning makes me feel great, I was relaxed and happy when I finished what I wanted to learn,), active learning (5 projects: My study life is very regular, I usually rush to study near exams, I often wander away in class, I often feel "There is no end for learning" in the study, I feel the time passes quickly when I study), attitude investment (6 projects: It's hard for me to put aside my studies, All the courses offered by the school I love to learn, I often arrive late or leave early, or even skip classes, I basically is the classroom, library, dormitory "3.1" life, I found that I had a lot to learn and to make up for, I can take the initiative to consult the data to solve the problem if I don't understand the knowledge), time investment (2 projects: I seldom play online because I study, I go to night school every day), learning methods (5 projects: I worked out a detailed system study plan, I never cheat in exams, For homework, I often do things carelessly, I selectively avoid some extracurricular activities because of learning, I have a clear learning goal), a total of 22 projects[6]. The questionnaire adopts self evaluation declarative sentence, including forward and reverse questions, completely inconsistent, representing 1 points, "comparison is not consistent", representing 2 points, "uncertainty" representing 3 points, "more consistent" representing 4 points, "fully consistent" representing 5 points. Using the Likert5 point scoring method, the higher the total score, the higher the degree of learning engagement, and vice versa.

TABLE I. OVERALL LEARNING ENGAGEMENT

\begin{tabular}{|c|c|}
\hline Class & Score \\
\hline A11 & 3.21 \\
\hline A12 & 3.26 \\
\hline A21 & 3.09 \\
\hline A22 & 3.03 \\
\hline B11 & 3.28 \\
\hline
\end{tabular}

C. The Degree of Learning Engagement

(1) General situation analysis

Statistical analysis was carried out for all the subjects, as shown in figure 1.

It can be seen that the overall distribution of College Students' learning investment is normal distribution, mostly concentrated in the vicinity of 3.3, less students scored less than 2.2. Students who scored more than 4.1 were less also.

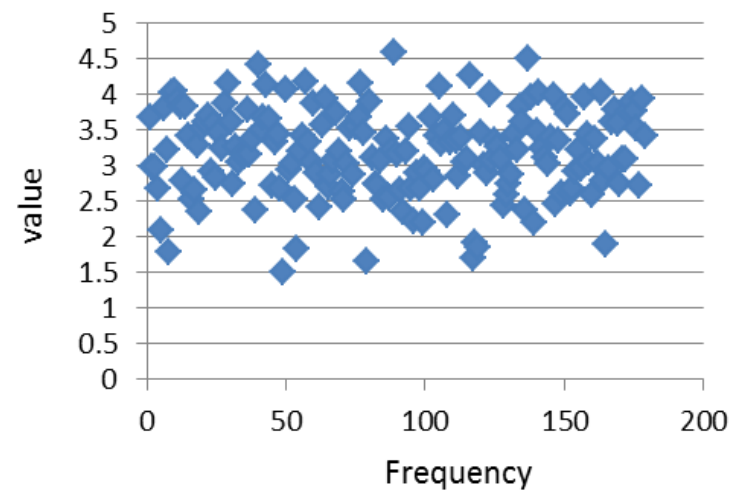

Fig. 1 The Overall Distribution of Learning Engagement

\section{(2) Comparison between classes}

Among the 5 classes surveyed, the B11 scored the highest score of 3.28, and the lowest score of the A22 was 3.03, indicating that there was a gap between the class and the students in the learning engagement. In addition, the 2011 grade automobile learning investment is also significantly lower than the 2010 of learning input, there is a big gap between grades, which is generally considered the lower grade of learning more serious point of view diametrically opposed. Through understanding with the relevant teacher in charge of class, teachers and counselors, the score of learning engagement is closely related to class learning style, B11 is generally considered a good style of study class (see Table 2).

TABLE II. LEARNING ENGAGEMENT IN EACH CLASS

\begin{tabular}{|c|c|c|}
\hline Content & Mean & Standard deviation \\
\hline Learning gains & 3.55 & 0.83 \\
\hline Active learning & 3.46 & 0.56 \\
\hline Attitude investment & 3.14 & 0.60 \\
\hline Time invested & 2.63 & 0.99 \\
\hline Learning methods & 3.15 & 0.76 \\
\hline Overall & 3.18 & 0.60 \\
\hline
\end{tabular}

(3) Analysis of factors influencing learning engagement

It is can be seen that more than 120 students think that the course interest affects their learning input, followed by teachers, students around, curriculum and professional approach from the figure. There are more than 60 students chose these projects, which requires our teachers to increase the fun of the course in the foundation to improve the level of their own. The school also creates a love learning environment. The students who choose their own factors and professional knowledge are not enough. From this, it can be explained that the students consider the objective factors in the analysis of reasons, and do not find the reasons from their own. There are only 6 students who choose the exam too simply, but the teachers reflect the situation that most of the examination is simple, which shows that most students don't have enough depth of knowledge. 


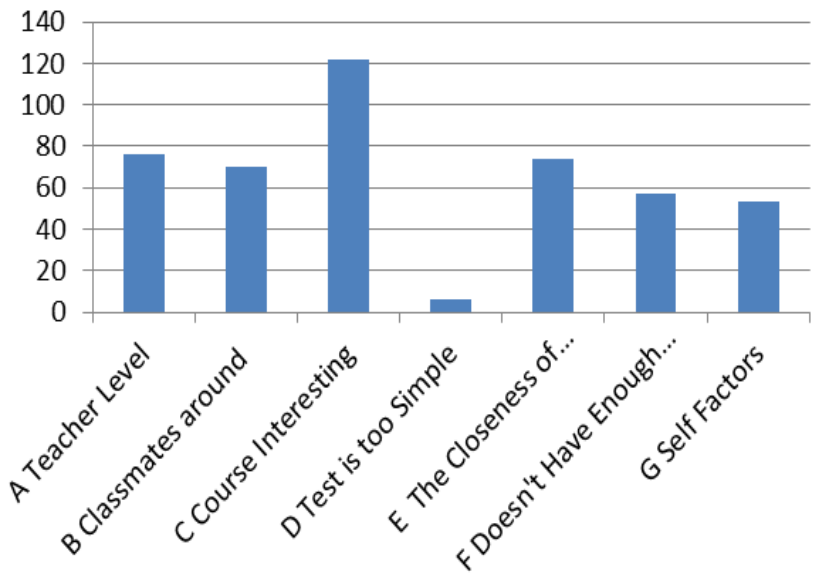

Fig. 2 Influence Factors Distribution of Learning Engagement

\section{Discussion}

(1) It can be seen that there is a great deviation between the classes in learning engagement, which is closely related to the style of study in the class. Therefore, it is necessary to strengthen the construction of study style.

(2) It can be seen from Figure 2 that only $31.8 \%$ of college students realized that the factors affecting learning were individuals. Most of the students attributed the influence factors to other external factors.

(3) It can be seen from the table 1 that the minimum score of the time spent on learning is only 2.63 points, which shows that most students do not devote more energy to their study. This may have a lot to do with the lack of learning pressure. Students study in their spare time just to finish their homework or to take a surprise test.

\section{CONCLUSION}

Through the investigation on the degree of learning engagement of students in Qilu University of Technology, the following conclusions can be drawn:

First, there is a big difference between the professional classes, and the main factor is the class style of study.

Second, college students will study the impact of factors attributed to the external environment, without taking into account their own circumstances.

Third, college students spend more time after school in various activities, and spend less time for learning.

\section{ACKNOWLEDGMENT}

The results of this study are funded by Postgraduate Education Innovation Program of Shandong Province (Grant NO.SDYY14025) and Teaching Research Project of QILU University of Technology (Research on Demand Forecasting of Applied Talents in Shandong Province Based on Large Data). Shandong Province Key Research and Development Program of China (2015GGX105005).

\section{REFERENCES}

[1] Tang Wei-hua, "Survey of Undergraduate Students ' Student Engagement in Huazhong University of Science and Technology", pp. 1-60, January, 2011. (In Chinese)

[2] Shi Fang Hua, "A new perspective of undergraduate education quality evaluation reform: Learning Engagement", Modern education management, vol. 2010, pp.51-54. (In Chinese)

[3] Astin,A.W.Achievin. "Education Excellence: A Critical Assessment of Priorities and Practices in HigherEducation".SanFrancisco, Jossey-Bass, 1985.

[4] Pascarella,E.T.College Environmental Influences on Learning and Cognitive Develop-Ment:A Critical Review and Synthesis. n J.Smart(Ed.).Higher education:Handbook of theory and research. ew York; Agathon,1985:1.

[5] Unknown, "A study on academic achievement and learning engagement of College Students", https://wenku.baidu.com/view/2a2d4508f78a6529647d53dc.html.(In Chinese)

[6] Unknown, "College Students' learning engagement questionnaire", https://www.wendangwang.com/doc/7ace9ebec47d22cc6e1953b5.(In Chinese) 